\title{
Substance $P$ and Cholecystokinin-like Immunoreactive Varicosities in Somatosensory and Autonomic Regions of the Rat Spinal Cord: A Quantitative Study of Coexistence
}

\author{
Mary M. Tuchscherer, Charles Knox, ${ }^{1}$ and Virglnia S. Seybold \\ University of Minnesota Medical School, Department of Cell Biology and Neuroanatomy and ${ }^{1}$ Department of Physiology, \\ Minneapolis, Minnesota 55455
}

\begin{abstract}
Substance P- and cholecystokinin-like immunoreactivities have been shown to coexist in some, but not all, dorsal root ganglion cell bodies of the rat. Quantitative immunofluorescence techniques were used in the present study to describe densities of substance P- and cholecystokinin-like immunoreactive varicosities in several spinal cord nuclei. By combining simultaneous immunofluorescent techniques on one tissue section with computerized image processing, coexistence of substance P- and cholecystokinin-like immunoreactivity in varicosities was also quantified. By comparing spinal cord regions between normal and unilateral dorsal rhizotomy affected animals, densities of substance P- and cholecystokinin-like immunoreactive varicosities associated with primary afferent neurons were established. To determine the densities of immunoreactive varicosities that were related to unmyelinated primary afferent fibers, data were compared between normal animals and those treated neonatally with capsaicin. Four major observations were made: (1) Substance P- and cholecystokinin-like immunoreactivity coexist in populations of varicosities in sensory and autonomic regions of rat spinal segment L6. (2) Within the superficial laminae of the dorsal horn, varicosities containing both substance P. and cholecystokinin-like immunoreactivity and cholecystokinin-like immunoreactivity alone are of primary afferent neuron origin, but those containing only substance P-like immunoreactivity are most likely of spinal or descending neuronal origin. (3) Capsaicin-insensitive cholecystokinin-like immunoreactive varicosities were present predominantly in lamina I. These data suggest some cholecystokinin-like immunoreactive varicosities are associated with myelinated primary afferent neurons. (4) Primary afferent fibers containing substance $P$ - and cholecystokininlike immunoreactivity project to intermediate gray regions of the rat spinal cord. A large proportion of these fibers are capsaicin sensitive, suggesting that they are unmyelinated.
\end{abstract}

\footnotetext{
Received Dec. 29, 1986; revised May 26, 1987; accepted May 29, 1987.

We are grateful to Drs. Robert Elde, Glenn Giesler, and Martin Wessendorf for their thoughtful comments during the preparation of the manuscript. We also extend our thanks to Dr. Nathan M. Appel for his assistance in developing the image-processing proiocols. These studies were supported by NIH Grant NS 17702 and Northwestern College of Chiropractic Medicine.

Correspondence should be addressed to Dr. Virginia S. Seybold, University of Minnesota Medical School, Department of Cell Biology and Neuroanatomy, 321 Church Street S.E., 4-135 Jackson Hall, Minneapolis, MN 55455.

Copyright (c) 1987 Society for Neuroscience $0270-6474 / 87 / 123984-12 \$ 02.00 / 0$
}

In recent years, the neuropeptides substance $\mathrm{P}$ (SP) and cholecystokinin octapeptide (CCK-8) have been suggested as neurotransmitters or neuromodulators of primary afferent neurons. Immunohistochemical studies have provided anatomical evidence in support of this hypothesis. SP-like immunoreactivity (SP-LI) has been reported in mammalian primary afferent neuron perikarya (Hökfelt et al., 1975a, b, 1976; Chan-Palay and Palay, 1977a, b; Cuello and Kanazawa, 1978; Panula et al., 1983; Kuo et al., 1985; Tuchscherer and Seybold, 1985a). Consistent with this localization, SP-LI has been shown to be reduced in the superficial laminae of the dorsal horn of the spinal cord following dorsal rhizotomy or ganglionectomy when assayed by radioimmunoassay (Kanazawa and Jessell, 1976; Jessell et al., 1979; Schultzberg et al., 1982), bioassay (Takahashi and Otsuka, 1975), and immunohistochemistry (Hökfelt et al., 1977; Barber et al., 1979; Seybold and Elde, 1980; Stroink et al., 1982a, b). Further, primary afferent cell bodies and fibers have been shown to be depleted of SP-LI content by neonatal treatment with capsaicin (Jessell et al., 1978; Gamse et al., 1980, 1981; Helke et al., 1981; Kessler and Black et al., 1981; Nagy et al., 1981), a chemical known to destroy small-diameter primary afferent neuron perikarya and unmyelinated C-fibers (Lawson and Nickels, 1980; Scadding, 1980; Lawson, 1981; Cervero and Plenderleith, 1984; Cervero et al., 1984). It has also been suggested that unmyelinated primary afferent fibers that exhibit SP-LI are permanently destroyed by neonatal capsaicin treatment (Nagy et al., 1981, 1983).

CCK-8-like immunoreactivity (CCK-8-LI) has also been localized in dorsal root ganglion perikarya (Larsson and Rehfeld, 1979; Dalsgaard et al., 1983; Tuchscherer and Seybold, 1985a) and has been measured in extracts of dorsal root ganglia (Schultzberg et al., 1982; Yaksh et al., 1982). However, the reported effects of dorsal rhizotomy and neonatal treatment with capsaicin on CCK-8-LI on central processes of mammalian primary afferent neurons have been contradictory. Several investigators report a reduction of CCK-8-LI from the dorsal horn following dorsal rhizotomy or neonatal treatment with capsaicin (Jancso et al., 1981; Priestly et al., 1982; Conrath-Verrier et al., 1984), while others report no reduction in immunoreactivity following these manipulations (Maderdrut et al., 1982; Marley et al., 1982; Schultzberg et al., 1982; Schroder, 1983). Further, although CCK-8-LI has been localized in a few of the same regions as SP-LI (Gibson et al., 1981; Sasek et al., 1984), no systematic study of the relationship of the 2 peptides within varicosities has been undertaken with respect to areas of termination of primary afferent neurons within the spinal cord. 
Recent evidence showing coexistence of SP-LI and CCK-8LI in some primary afferent neuron perikarya (Dalsgaard et al., 1983) has prompted more detailed study of the relationship between SP and CCK-8 in primary afferent neurons. Recent work by our laboratory (Tuchscherer and Seybold, 1985a) suggests that 4 populations of primary afferent perikarya can be distinguished using criteria of cell size and SP-LI/CCK-8-LI content: (1) small cells ( $<20 \mu \mathrm{m}$ in diameter) that contain SPLI alone; (2) small cells that contain both SP-LI and CCK-8$\mathrm{LI}$; (3) intermediate-sized cells $(20-45 \mu \mathrm{m}$ in diameter) that contain CCK-8-I.I alone; and (4) intermediate-sized cells that contain both SP-LI and CCK-8-LI. Current work by several investigators (Harper and Lawson, 1985; Lee et al., 1986) suggests that cell size may be correlated with axon size for populations of primary afferent neurons. On the basis of these studies, we hypothesize that the small SP-LI and SP-LI + CCK-8-LI cell populations give rise to unmyelinated $\mathrm{C}$-fibers, while intermediate-sized cell populations of SP-LI + CCK-8-LI and CCK8 -LI give rise to thinly myelinated $\mathrm{A}$-delta fibers.

The present report extends our studies of SP-LI, CCK-8-LI, and their coexistence to varicosities with termination sites of primary afferent neurons in the spinal cord. Primary afferent neurons that give rise to unmyelinated $\mathrm{C}$-fibers have been shown to terminate largely in laminae I and II of the spinal cord on the basis of conduction velocity (Kumazawa and Perl, 1976, 1978) and intracellular labeling with the lectin Phaseolus vulgaris leukoagglutinin (PHA-L) (Sugiura et al, 1986). Using electrophysiological criteria (Light et al., 1979), as well as intraaxonal filling with HRP (Mense et al., 1981), thinly myelinated A-delta fibers associated with primary afferent neurons have been shown to terminate in laminae I, II (outer), V, and X. In addition to these areas, primary afferent fibers presumed to be of small diameter have also been shown to terminate in areas of the spinal cord associated with autonomic control. Employing transganglionic transport of HRP, the nucleus of the dorsal gray commissure (DGC) (Morgan et al., 1981; Nadelhaft et al., 1983; Nadelhaft and Booth, 1984) and the sacral parasympathetic nucleus (SPN) (deGroat et al., 1978; Morgan et al., 1981; Nadelhaft et al., 1983; Nadelhaft and Booth, 1984) have been shown to contain central projections of dorsal root ganglion cells.

In the present study, changes in the density of SP-LI and CCK-8-LI varicosities following dorsal rhizotomy were used to define the density of immunoreactive varicosities associated with primary afferent axons within discrete regions of the spinal cord. Changes in densities of immunoreactive varicosities after neonatal treatment with capsaicin were used to determine the proportion of these peptide immunoreactive varicosities which were related to unmyelinated versus thinly myelinated axons with in each region. Changes in the densities of SP-I I and CCK8-LI varicosities after each of the treatments were determined using computerized image analysis of tissue sections. Co-existence of SP-LI and CCK-8-LI in varicosities in the spinal cord was determined via simultaneous immunofluorescent localization of immunoreactivity related to these two peptides.

\section{Materials and Methods}

Adult, female Sprague-Dawley rats (200-300 gm) were used throughout the study. Animals were allowed access to food and water ad libitum and were maintained under $12 \mathrm{hr}$ light/12 hr dark conditions. Four groups of animals were studied: a normal group $(n=5)$, a group having undergone unilateral lumbosacral dorsal rhizotomy $(n=6)$, a group treated neonatally with capsaicin $(n=5)$, and a control group treated with the vehicle for the capsaicin treatment $(n=4)$.

Unilateral dorsal rhizotomy. Six animals were anesthetized using 0.35 $\mathrm{gm} / \mathrm{kg}$ (i.p.) chloral hydrate (Baker) and $0.25 \mathrm{mg} / \mathrm{kg}$ (i.p.) diazepam (Roche). Bilateral laminectomies were performed on spinal vertebrae L4, L5, L6, S1, and S2. Dorsal root ganglia from each level were exposed, and the dura mater surrounding dorsal roots was incised. The individual roots were elevated with forceps and transected using a microdissecting scissors (Tiemann). Care was taken not to disrupt the radicular arteries surrounding the dorsal roots during the procedure. All surgical procedures were carried out using a Nikon dissecting scope. Gelfoam (Upjohn) was packed around the exposed spinal cord for protection and to reduce bleeding of surrounding tissues following the procedure. The wound was sutured and the animals allowed to recover. The animals were closely monitored during their $9 \mathrm{~d}$ survival, and their bladders were expressed daily.

Neonatal capsaicin treatment. One-half of the pups (19 animals) from 4 litters were chosen at random and were treated on neonatal day 2 with $0.05 \mathrm{gm} / \mathrm{kg}$ (s.c., approximately $50 \mu \mathrm{l}$ per pup) of capsaicin (Sigma) (Jancso et al., 1977). The remaining pups were treated with the vehicle ( $80 \%$ saline, $10 \%$ Tween 80 , and $10 \%$ absolute ethanol; $50 \mu \mathrm{l}$ ). After 45 $\mathrm{d}$, the animals were tested for capsaicin sensitivity (Gamse, 1982). Briefly, a dilute solution $(0.1 \mathrm{mg} / \mathrm{ml})$ of capsaicin was gently dropped onto the corneal surface of one eye of each animal, and the response recorded. Those animals that received vehicle treatments responded with a vigorous grooming behavior directed at the eye, while those that received capsaicin treatment generally did not exhibit this behavior. Five female animals that did not respond to the corneal capsaicin application were used as the capsaicin-treated group in the immunohistochemical studies. Age-matched rats were selected from the vehicle-treated group for comparison.

Preparation of tissue for immunofluorescence. In all cases, the animals were perfused under anesthesia through the aorta using Zamboni fixative (Stefanini et al., 1967). Spinal segment L6 was removed and stored in the fixative overnight. Spinal segment L6 was chosen for study since retrograde transport of HRP from the proximal end of a severed pelvic nerve has been shown to label perikarya in L6-SI dorsal root ganglia and parasympathetic preganglionic neurons in spinal segments L6-S1 in the rat (Nadelhaft and Booth, 1984). Thus, L6 segment includes regions related to autonomic function as well as somatosensory function. After fixation, the tissue was transferred to a 5\% sucrose solution in 0.1 $\mathrm{M}$ phosphate buffer, $\mathrm{pH} 7.2$, at $4^{\circ} \mathrm{C}$ for storage. To avoid bias during quantification, cord segments were coded and mounted in a block for sectioning by one investigator, while further tissue manipulation and quantification of varicosities were carried out by another investigator. Five micrometer horizontal sections were cut through the tissue block using a Bright cryostat.

Two techniques were used to determine the boundaries of spinal cord laminae I and II: first, the boundaries were determined in the immunofluorescence-stained sections using standard transmitted dark-field illumination, and camera lucida drawings were made. Second, these drawings were compared with adjacent $5 \mu \mathrm{m}$ sections stained for myelin with osmiun tetroxide. Both methods showed that the laminae I/II border occurred approximately $20 \mu \mathrm{m}$ ventral to the dorsal columns, at a point medial and adjacent to the dorsal root entry zone, while the laminae II/III border fell approximately $120 \mu \mathrm{m}$ ventral to the dorsal columns.

Immunofluorescence microscopy. The immunoreactivity for SP and CCK-8 was localized using a method for simultaneous immunofluorescence (Erichsen et al., 1982; Wessendorf and Elde, 1985). Briefly, the method is as follows: after rehydration of the sections, a mixture of primary antisera diluted in a solution containing $0.3 \%$ Triton $X-100$ in PBS [1:200 rat anti-SP (monoclonal NCL 52, Sera Lab) and 1:100 rabbit anti-CCK-8 (R182D, Dr. R. P. Elde, University of Minnesota)] was incubated on the sections overnight at $4^{\circ} \mathrm{C}$. Following three $15 \mathrm{~min}$ washes in PBS, a mixture containing secondary antibodies [1:20 goat anti-rat IgG labeled with fluorescein isothiocyanate (FITC) and 1:10 goat anti-rabbit IgG labeled with lissamine rhodamine sulfanyl chloride (L-RSC)] was incubated on the sections for $1 \mathrm{hr}$ at room temperature. After staining, the sections were viewed with an Olympus BH-2 RFL fluorescence microscope using epi-illumination. FITC and L-RSC were visualized independently using selective filter combinations (FITC: excitation, $450-490 \mathrm{~nm} /$ emission, $520-560 \mathrm{~nm}$; L-RSC excitation, 545 $\mathrm{nm} /$ emission, 590 long pass). The specificity of the fluorescence of the 2 fluorochromes was tested as follows: (1) Sections stained with rat anti- 


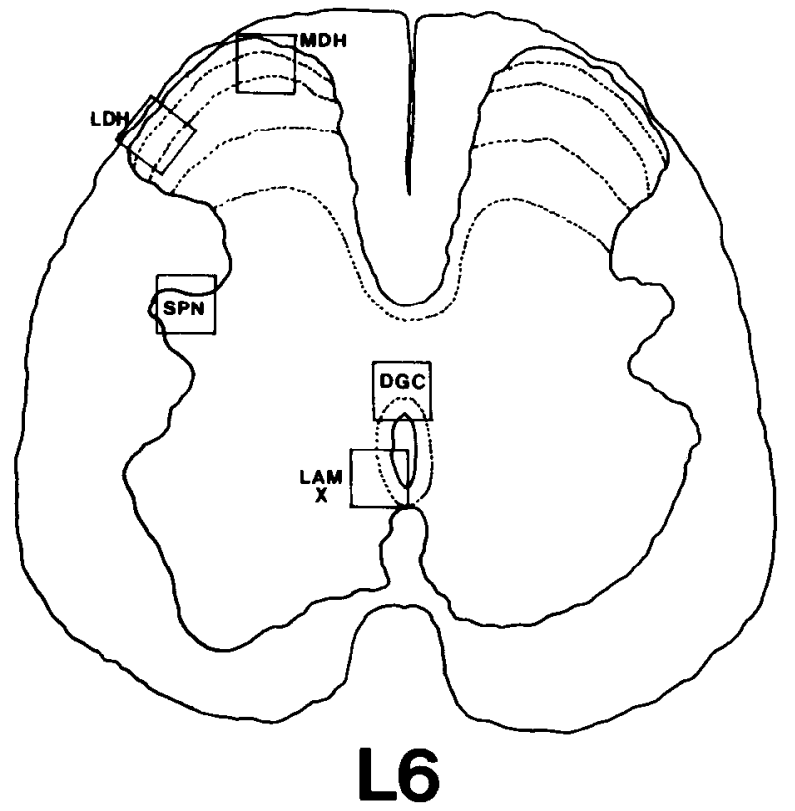

Figure 1. Diagram of spinal segment L6 illustrating areas sampled for quantification. Areas included 2 regions of the superficial dorsal horn [a medial $(M D H)$ and a lateral $(L D H)$ region], the nucleus of the dorsal gray commissure $(D G C)$, the sacral parasympathetic nucleus $(S P N)$, and the area surrounding the central canal [lamina $\mathrm{X}(L A M X)$ ].

SP and goat anti-rat IgG-FITC were illuminated as for L-RSC excitation, and (2) sections stained with rabbit anti-CCK-8 and goat anti-rabbit IgG-L-RSC were illuminated as for FITC excitation. Neither method revealed fluorescence.

Absorption controls were used to determine the specificity of each of the antibodies used. When each diluted primary antibody was treated for $6-8 \mathrm{hr}$ with the homologous antigen $(10 \mu \mathrm{g} / \mathrm{ml}$ diluted serum), no positive staining was observed in any of the test sections. Heterologous controls were also performed. When diluted anti-SP was absorbed with $10 \mu \mathrm{g} / \mathrm{ml}$ of CCK -8 , the staining quality of the anti-SP antibody was unaffected. The parallel test was performed on the CCK-8-antiserum, and again, no cross-reactivity was demonstrated. Tests of the secondary antibodies were also made to establish their immunological specificity. When sections were incubated in the monoclonal rat anti-SP and the secondary goat anti-rabbit L-RSC, no positive staining resulted. Similar results were obtained using the rabbit anti-CCK- 8 and the secondary goat anti-rat-FITC. Also, on sections stained with one primary antibody and both secondary antibodies, only fluorescence of the immunologically complementary antibody was observed.

In light of current concern over the molecular identity of CCK-8-LI in primary afferent neurons (Ju et al., 1986), additional controls were performed. The technique of Larsson (1981) was used to test crossreactivity of both the rat anti-SP antibody and rabbit anti-CCK- 8 antisera with their homologous antigens and 15 additional antigens localized to the dorsal horn of the spinal cord. Homologous antigens $(10,1.0$, $0.1,0.01$, and $0.001 \mathrm{nmol} / 2 \mu \mathrm{l})$ and heterologous antigens $(1.0 \mathrm{nmol} / 2$ $\mu 1)$ were applied to Whatman No. 1 filter paper and immobilized by paraformaldehyde vapor in vacuo. The paper was then treated as tissue and was processed for immunofluorescence in the exact manner as described above. The antigens tested were somatostatin(1-28), somatostatin(15-28), calcitonin gene-related peptide (CGRP, 1-37 and 2837), neurokinin $A$, neurokinin $B$, vasoactive intestinal polypeptide (VIP), galanin, 5-hydroxytryptamine, dynorphin $\mathrm{A}(1-8)$, dynorphin $\mathrm{B}$, methionine enkephalin, leucine enkephalin, neurotensin, oxytocin, and vasopressin. In almost all cascs, the cxtent of cross-rcactivity with heterologous peptides was less than $0.01 \%$. The exceptions were cross-reactivity of the 2 CGRP peptides with anti-CCK. However, in these cases, the amount of cross-reactivity for CGRP 1-37 and CGRP $\mathrm{C}_{28-37}$ was determined to be less than 1.0 and $0.1 \%$, respectively. Further heterologous absorption controls were also performed on spinal cord tissue sections. It was found that $100 \mu \mathrm{M} \mathrm{CGRP}_{1-37}$ and $10 \mu \mathrm{M} \mathrm{CGRP}{ }_{28-37}$ were required to completely absorb immunostaining by the CCK-8 antiserum, whereas only $0.01 \mu \mathrm{M}$ CCK-8 was required to abolish the staining of the CCK- 8 antiserum at the $1 / 100$ dilution used in the present study. In addition, adjacent $5 \mu \mathrm{m}$ sections through several levels of the neuroaxis were stained alternately with an antiserum against CGRP (Amersham) and the CCK-8 antiserum to establish areas of specific CGRP-immunoreactive varicosities that were not also CCK-8 immunoreactive. Using the Konig and Klippel stereotaxic atlas (1963) as a reference, CGRP-LI alone was observed in the most dorsal aspect of the piriform cortex and in a region of the lateral hypothalamus medial to the ventromedial aspect of the internal capsule. The coronal sections of the rat hypothalamus spanned approximate stereotaxic coordinates A3290 to A3430.

Quantification methods. Five areas of termination of primary afferent neurons in rat spinal segment L6 were studied. These areas were (Fig. 1): laminae I + II (a lateral and a medial area), lamina $X$ (including the ventral longitudinal bundle), the nucleus of the dorsal gray commissure (DGC), and the sacral parasympathetic nucleus (SPN). Each field quantified measured $0.017 \mathrm{~mm}^{2}$ at $250 \times$ magnification. The FITC and L-RSC images for each field (representing SP-LI and CCK-8-LI, respectively) were analyzed for each of the 5 areas studied from one side of one section of each spinal segment. In the segments from animals having undergone unilateral rhizotomy, areas ipsilateral and contralateral to the lesion were analyzed. For all experiments, one section from each animal for each region was analyzed. The section was randomly chosen, though sections exhibiting high, nonspecific background or autofluorescent material in the mounting media were discarded.

Computerized image processing was used to quantify the density of immunoreactive varicosities and estimate the coexistence of SP-LI and CCK-8-LI. The system used in the present study consisted of an International Imaging Systems model 75 Image Processor, which runs 575 software on a MASSCOMP 535 minicomputer. Video images were obtained through a silicon-intensified target camera (DAGE-MTI model 66 ), digitized, and stored as 8 bit, $512 \times 512$ pixel images in frame buffer memory. In practice, the FITC fluorophore was illuminated with the appropriate filter set, and the field was digitized and stored in one frame buffer. This same field was then illuminated for excitation of the L-RSC fluorophore, digitized, and stored in a separate frame buffer. In the process of obtaining these pairs of digitized images, neither the plane of focus nor the intensity of illumination was changed. The contrast of each image was enhanced using the Wallis function (International Imaging Systems) in order to sharpen the boundaries of immunoreactive varicosities (Fig. 2, $A$ and $B$ ). Pixels representing areas of immunoreactive varicosities in the FITC image were assigned a green color (Fig. $2 C$ ) and stored in a frame buffer, whereas pixels representing areas of immunoreactive varicosities in the L-RSC image were assigned a red color (Fig. $2 D$ ) and stored in a separate frame buffer. The frame buffers containing the red and green images were then summed. As a result, individual varicosities containing both FITC and L-RSC fluorophores appeared yellow (Fig. 2E). Yellow-coded pixels were stored in a fifth frame buffer. The total colored area of each image was then quantified. The number of immunoreactive varicosities was calculated as follows:

$\frac{\begin{array}{c}\text { Total number of pixels } \\ \text { of one color/field }\end{array}}{\begin{array}{c}\text { Average number of } \\ \text { colored pixels/varicosity }\end{array}}=\begin{gathered}\text { Number of } \\ \text { varicosities/field }\end{gathered}$

The average number of pixels/varicosities varied among the areas studied, with a range of $30 \pm 3$ pixels/varicosity in lamina $X$ to $100 \pm 6$ pixels/varicosity in the superficial dorsal horn. Thus, the data are expressed as the calculated number of SP-LI, CCK-8-LI, or SP-LI/CCK-8LI varicosities per field. Significant differences in the number of varicosities quantified between control and treatment groups were determined using Student's $t$ test.

A test was performed to estimate the degree of spurious overlap in SP-LI and CCK-8-LI varicosities where coexistence does not occur. Two images (one SP-LI, one CCK-8-LI) from the same area from different animals were viewed simultaneously. The area selected was the medial region of laminae I + II as this was the area found to contain the greatest density of varicosities for both SP-LI and CCK-8-LI. One image was then moved in an effort to maximize the numbers of varicosities that overlapped. The number of random overlapping varicosities was calculated to be $14 \pm 5$ (average of 2 trials for each of 5 pairs of sections), which is approximately $6 \%$ of the total SP-LI+CCK-8-LI varicosities in this region. 

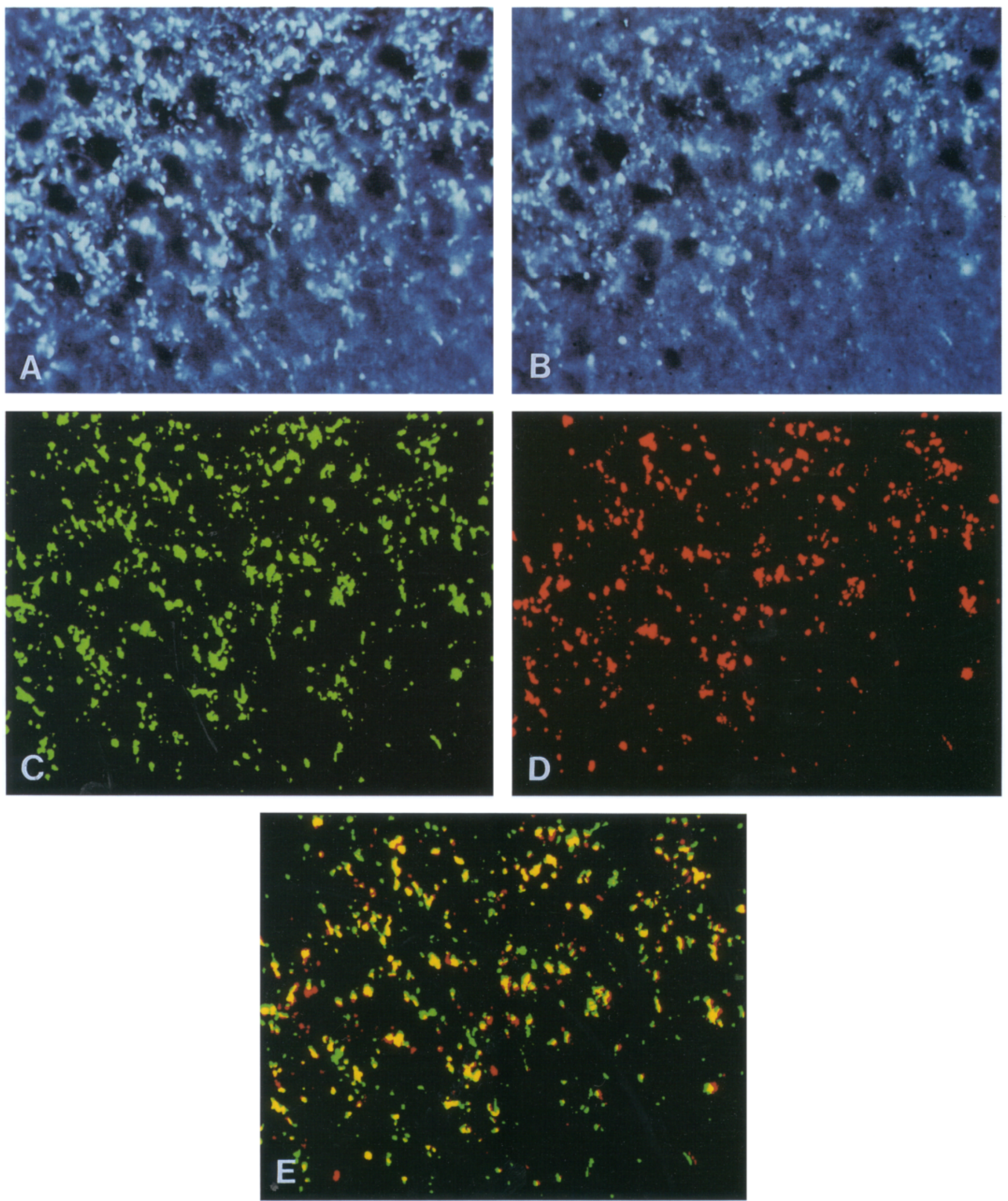

Figure 2. Images produced by computerized image processing illustrating the quantitative method. The region of analysis in this example is the superficial laminae of the medial dorsal horn of the rat spinal segment L6. $A$, Image of substance P-like (SP) immunofluorescence visualized with a monoclonal rat anti-SP primary antibody and fluorescein-conjugated goat anti-rat secondary antiserum. $C$, Through computerized image processing, the areas of fluorescent varicosities are selectively stored as a green image. The total green area can be quantified. $B$, Image of cholecystokininoctapeptide-like (CCK-8) immunofluorescence visualized with a rabbit anti-CCK-8 primary antiserum and lissamine rhodamine-conjugated goat anti-rabbit secondary antiserum. $D$, Areas of CCK-8 varicosities are stored as a red image. $E$, Images $C$ and $D$ of SP and CCK-8 immunoreactivity, respectively, have been superimposed, and areas of coexistence appear yellow. The yellow area can be quantified separately from the green and red areas. 
Table 1. Quantification of coexistence of SP-LI and CCK-8-LI in varicosities within rat spinal segment L6

\begin{tabular}{|c|c|c|c|c|}
\hline \multirow[b]{2}{*}{ Region } & \multicolumn{2}{|l|}{ SP-LI } & \multicolumn{2}{|l|}{ CCK-8-LI } \\
\hline & Varicosities $^{a}$ & Coexistence $^{b}$ & Varicosities $^{a}$ & Coexistence $^{c}$ \\
\hline \multicolumn{5}{|l|}{ Laminae I + II } \\
\hline Lateral & $425 \pm 20$ & $0.39 \pm 0.03$ & $226 \pm 26$ & $0.67 \pm 0.03$ \\
\hline Medial & $573 \pm 54$ & $0.35 \perp 0.04$ & $336 \pm 45$ & $0.66 \pm 0.03$ \\
\hline Lamina $\mathrm{X}$ & $263 \pm 23$ & $0.14 \pm 0.03$ & $107 \pm 29$ & $0.36 \pm 0.06$ \\
\hline Dorsal gray commissure & $433 \pm 35$ & $0.10 \pm 0.02$ & $155 \pm 25$ & $0.28 \pm 0.01$ \\
\hline Sacral parasympathetic nucleus & $301 \pm 32$ & $0.21 \pm 0.05$ & $124 \pm 22$ & $0.50 \pm 0.04$ \\
\hline
\end{tabular}

All values represent means \pm SEM from 5 animals.

${ }^{a}$ Number of varicosities $/ 0.017 \mathrm{~mm}^{2}$.

b Proportion of SP varicosities that also contain CCK.

c Proportion of CCK varicosities that also contain SP.

\section{Results}

\section{Normal animals}

The density of calculated varicosities in each area for each peptide is shown in Table 1. For all 5 areas studied, there were about twice as many SP-LI varicosities as CCK-8-LI varicosities. There appeared to be a strong parallel between the rank order of densities of immunoreactive varicosity populations for both peptides: laminae I + II > DGC $>$ SPN $>$ lamina X. This pattern, however, did not extend to the proportions of varicosities containing both SP-LI and CCK-8-LI within each area (Table 1). In this case the rank order was as follows: laminae $\mathrm{I}+\mathrm{II}>\mathrm{SPN}>$ lamina $\mathrm{X}>\mathrm{DGC}$. The proportion of CCK8-LI varicositics that contained SP-LI was twice the proportion of SP-LI varicosities that contained CCK-8-LI for all regions sampled.

The data in Table 1 were used to separate the varicosities into 3 populations: those containing SP-LI without CCK-8-LI (to be defined operationally as "SP-LI alone"), CCK-8-LI without SPLI (defined as "CCK-8-LI alone"), and those containing both SP-LI and CCK-8-LI (SP-LI/CCK-8-LI; Table 2). The density of varicosities containing SP-LI alone in each area was always the greatest and was at least 3-fold greater than the density of varicosities containing $\mathrm{CCK}-8-\mathrm{LI}$ alone in all 5 areas. In 2 of the areas, laminae I + II and the SPN, the density of varicosities containing SP-LI/CCK-8-LI was greater than the density of CCK8 -LI alone varicosities, while in lamina $X$ and DGC there were only half as many SP-LI/CCK-8-LI varicosities as CCK-8-LI alone varicosities per field.

\section{Experimental animals}

The effects of dorsal rhizotomy and neonatal capsaicin treatment on the 3 populations of immunoreactive varicosities in laminae $I+$ II and lamina $X$ are shown in Table 3. Neither dorsal rhizotomy nor capsaicin treatment had a significant effect on the density of SP-LI alone varicosities in laminae I + II. In contrast, both dorsal rhizotomy and neonatal capsaicin treatment caused almost a complete loss of SP-LI/CCK-8-LI varicosities from laminae I + II. Dorsal rhizotomy treatment caused a $90 \%$ decrease in the number of CCK-8-LI alone varicosities, whereas capsaicin treatment caused only a $50 \%$ decrease in these varicosities. It was noteworthy that the $\mathrm{CCK}-8-\mathrm{LI}$ varicositics that remained following neonatal capsaicin treatment were found predominantly in lamina I (Fig. 3).

Determination of the effect of unilateral dorsal rhizotomy on the density of immunoreactive varicosities in lamina $X$ by comparing the lesioned side to the nonlesioned side may be invalid since it is known that at lumbosacral levels lamina $\mathrm{X}$ receives bilateral input in rat (Nadelhaft and Booth, 1984) and in other species (Light et al., 1979: monkey; Morgan et al., 1981: cat). However, the weight and sex of normal and rhizotomized animals were nearly the same, and the processing of tissue sections was consistent in the 2 groups. Therefore, statistical comparisons between normal and rhizotomized animals were made for this region. Following unilateral dorsal rhizotomy, the densities of varicosities on the nonlesioned side for all 3 populations were significantly decreased compared with normal animals. In con-

Table 2. Quantification of coexistence of SP-LI alone and CCK-8-LI alone in varicosities within rat spinal segment L6

\begin{tabular}{lccc} 
Region & SP-LI alone & CCK-8-LI alone & $\begin{array}{l}\text { SP }+ \text { CCK- } \\
8 \text {-LI }\end{array}$ \\
\hline Laminae I + II & & & \\
$\quad$ Lateral & $276 \pm 23$ & $78 \pm 11$ & $149 \pm 18$ \\
$\quad$ Medial & $349 \pm 34$ & $112 \pm 21$ & $224 \pm 30$ \\
Lamina X & $228 \pm 27$ & $74 \pm 3$ & $34 \pm 6$ \\
Dorsal gray commissure & $391 \pm 39$ & $113 \pm 18$ & $43 \pm 8$ \\
Sacral parasympathetic nucleus & $237 \pm 27$ & $49 \pm 10$ & $63 \pm 16$
\end{tabular}

All values represent means \pm SEM from 5 animals. The area of quantification was $0.017 \mathrm{~mm}^{2}$. 

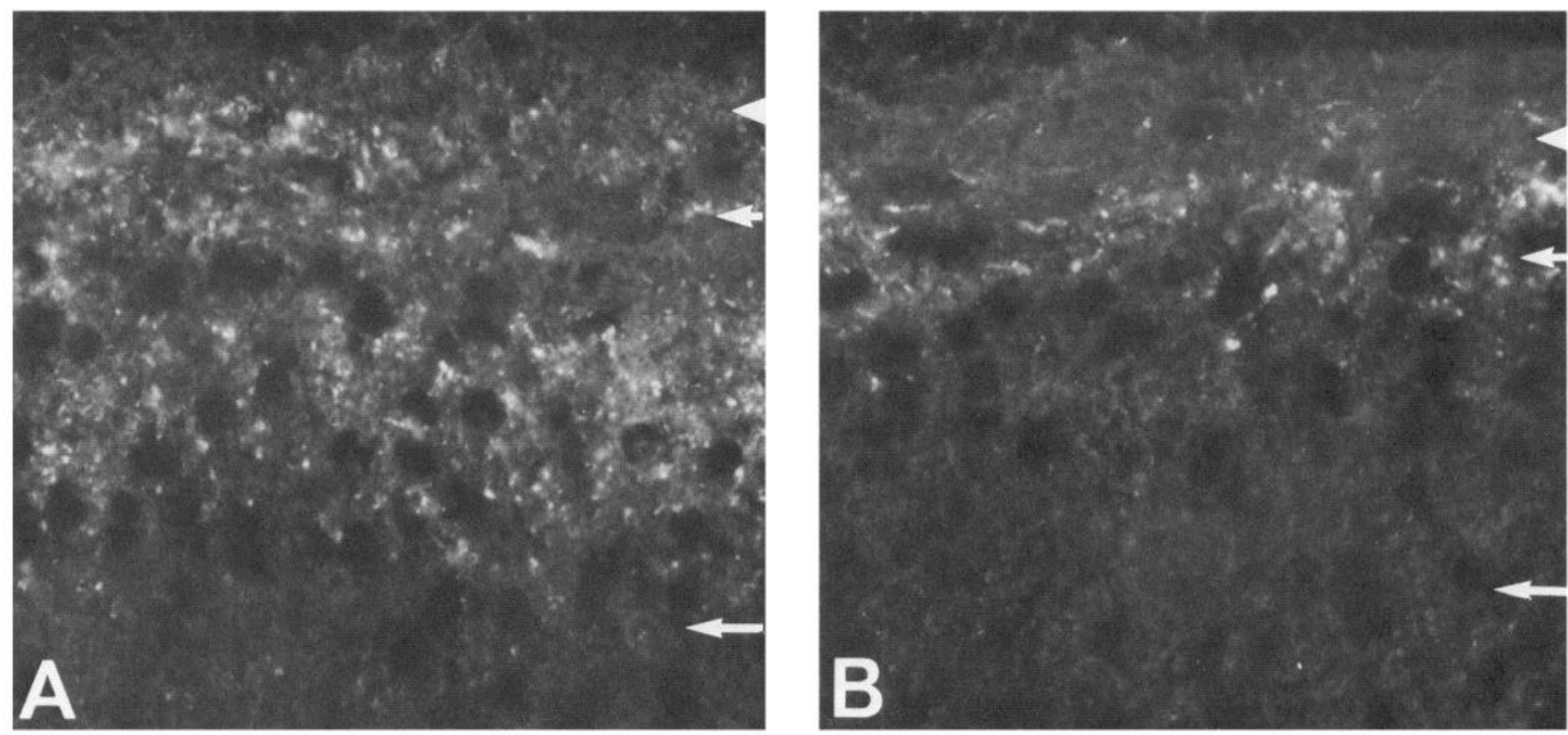

Figure 3. Photomicrograph illustrating the effect of neonatal capsaicin treatment on the density of CCK-8-LI varicosities in the superficial laminae of the dorsal horn. A, CCK-8-LI within laminae I and II of a normal animal. B, After neonatal treatment with capsaicin. In both photomicrographs, the arrowhead delineates the approximate gray matter/white matter boundary; the short arrow delineates the approximate laminae I and II boundary; and the long arrow, the laminae II and III boundary.

trast, the densities on the lesioned side were not significantly different from normal for the SP-LI alone and CCK-8-LI alone populations, though the SP-LI/CCK-8-LI population was significantly depleted. For capsaicin-treated animals, we found that there were significant decreases in all 3 populations of varicosities studied. There were nearly complete losses of SP-LI/CCK8 -LI and CCK-8-LI alone varicosity populations, and a $30 \%$ decrease in the number of SP-LI alone varicosities per field. Figure 4 shows that the most dramatic loss of immunoreactive structures was in a bundle of fibers ventral to the central canal.

The effect of dorsal rhizotomy and neonatal capsaicin treatment on the 3 populations of peptide-containing varicosities in the DGC and SPN are shown in Table 4. Since the DGC is also a midline region and known to receive bilateral input in rat (Nadelhaft and Booth, 1984) and in cat (Morgan et al., 1981), data from rats that received dorsal rhizotomies were compared with normal animals. The densities of all 3 categories of vari- cosities within the DGC were decreased by unilateral dorsal rhizotomy. Neonatal capsaicin treatment also caused a significant decrease in the densities of all 3 populations of immunoreactive varicosities in the DGC. Populations of CCK-8-LI alone and SP-LI/CCK-8-LI varicosities were almost completely lost, whereas there was a $45 \%$ decrease in the number of SP-LI alone varicosities per field.

Within the SPN, unilateral dorsal rhizotomy similarly caused significant decreases in all 3 populations of immunoreactive varicosities. An approximately $35 \%$ decrease in the density of SP-LI alone varicosities, and 60 and $80 \%$ decreases in the density of CCK-8-LI alone and SP-LI/CCK-8-LI varicosities were seen, respectively. In contrast to the effects of dorsal rhizotomy, neonatal capsaicin treatment had no significant effect on SP-LI alone varicosities in SPN. The loss of CCK-8-LI alone and SP$\mathrm{LI} / \mathrm{CCK}-8$-LI due to capsaicin in the SPN was virtually complete.

Table 3. Effect of dorsal rhizotomy and capsaicin treatment on the density of SP-LI alone, CCK-8-LI alone, and SP + CCK-8-LI containing varicosities within somatosensory areas

\begin{tabular}{|c|c|c|c|c|c|c|c|}
\hline \multirow[b]{2}{*}{ Group } & \multicolumn{3}{|c|}{ Laminae I + II } & \multicolumn{4}{|l|}{ Lamina $\mathrm{X}$} \\
\hline & $\begin{array}{l}\text { SP-LI } \\
\text { alone }\end{array}$ & $\begin{array}{l}\text { CCK-8-LI } \\
\text { alone }\end{array}$ & $\begin{array}{l}\text { SP + CCK- } \\
8-\mathrm{LI}\end{array}$ & $\begin{array}{l}\text { SP-LI } \\
\text { alone }\end{array}$ & $\begin{array}{l}\text { CCK-8- } \\
\text { LI alone }\end{array}$ & $\begin{array}{l}\text { SP }+ \\
\text { CCK-8-LI }\end{array}$ & $N$ \\
\hline Normal & $349 \pm 34$ & $112 \pm 21$ & $224 \pm 29$ & $228 \pm 27$ & $74 \pm 3$ & $34 \pm 6$ & 5 \\
\hline \multicolumn{8}{|l|}{ Dorsal rhizotomy } \\
\hline Nonlesioned side & $347 \pm 22$ & $179 \pm 22$ & $221 \pm 14$ & $141 \pm 19 \dagger$ & $40 \pm 4 \dagger$ & $5 \pm 2 \dagger$ & 6 \\
\hline Lesioned side & $315 \pm 26$ & $28 \pm 4^{* *}$ & $9 \pm 2^{* *}$ & $208 \pm 30$ & $64 \pm 20$ & $9 \pm 3 \dagger$ & 6 \\
\hline \multicolumn{8}{|l|}{ Capsaicin treatment } \\
\hline Vehicle & $278 \pm 26$ & $87 \pm 11$ & $127 \pm 13$ & $269 \pm 18$ & $32 \pm 7$ & $15 \pm 3$ & 4 \\
\hline Capsaicin & $242 \pm 29$ & $43 \pm 9^{*}$ & $41 \pm 6^{* *}$ & $189 \pm 25^{*}$ & $7 \pm 2 *$ & $3 \pm 0.8^{*}$ & 5 \\
\hline
\end{tabular}

All values represent means \pm SEM. $N=$ number of animals in each group. The area of quantification was $0.017 \mathrm{~mm}^{2}$. Student's $t$ test results: significantly less than control at $p<0.01\left(^{*}\right)$ or $p<0.001\left(^{* *}\right)$ or than normal at $p<0.01(\dagger)$. 

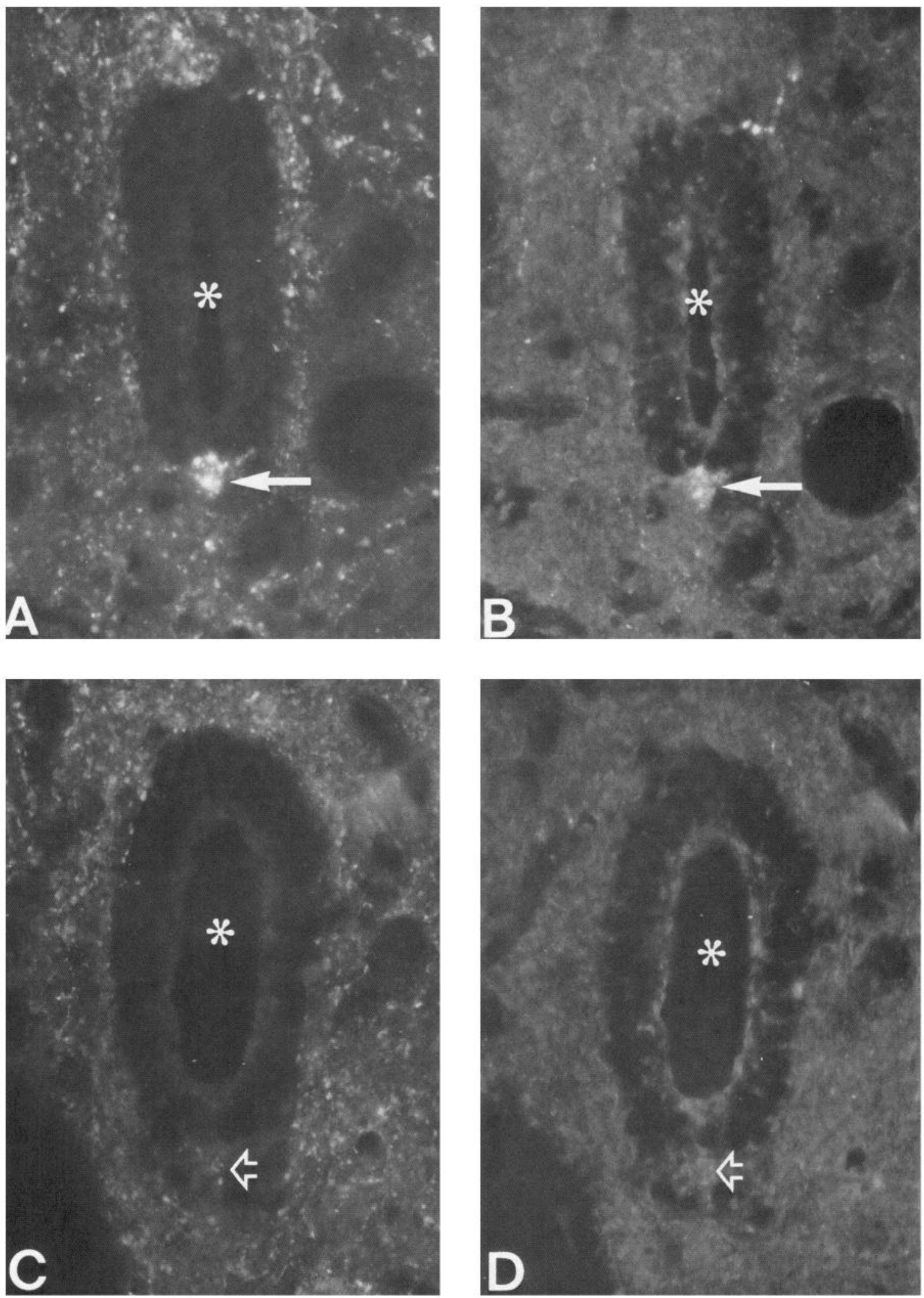

Figure 4. Photomicrographs illustrating the effect of neonatal capsaicin treatment on SP-LI and CCK-8-LI varicosities within lamina X. SP-LI is shown in $A$ and $C$, CCK-8-LI in $B$ and $D$. The central canal is marked by an asterisk. The closed arrows in $A$ and $B$ indicate a longitudinally oriented bיndle of immunoreactive fibers ventral to the central canal in a normal animal. Panels $C$ and $D$ show that after capsaicin treatment, no fibers immunoreactive for either SP-LI or CCK-8-LI remain within the region of the ventral bundle (open arrows). 
Table 4. Effect of dorsal rhizotomy and capsaicin treatment on the density of SP-LI alone, CCK-8-LI alone, and SP + CCK-8-LI containing varicosities within autonomic areas

\begin{tabular}{|c|c|c|c|c|c|c|c|}
\hline \multirow[b]{2}{*}{ Group } & \multicolumn{3}{|c|}{ Dorsal gray commissure } & \multicolumn{3}{|c|}{ Sacral parasympathetic nucleus } & \multirow[b]{2}{*}{$N$} \\
\hline & $\begin{array}{l}\text { SP-LI } \\
\text { alone }\end{array}$ & $\begin{array}{l}\text { CCK-8-LI } \\
\text { alone }\end{array}$ & $\begin{array}{l}\text { SP + CCK- } \\
8 \text {-LI }\end{array}$ & $\begin{array}{l}\text { SP-LI } \\
\text { alone }\end{array}$ & $\begin{array}{l}\text { CCK-8-LI } \\
\text { alone }\end{array}$ & $\begin{array}{l}\text { SP + CCK- } \\
8 \text {-LI }\end{array}$ & \\
\hline Normal & $391 \pm 39$ & $113 \pm 18$ & $43 \pm 8$ & $237 \pm 27$ & $49 \pm 10$ & $63 \pm 16$ & 5 \\
\hline \multicolumn{8}{|l|}{ Dorsal rhizotomy } \\
\hline Nonlesioned side & $272 \pm 35 \dagger$ & $72 \pm 3 \dagger$ & $17 \pm 5 \dagger$ & $263 \pm 33$ & $90 \pm 8$ & $59 \pm 15$ & 6 \\
\hline Lesioned side & $a$ & a $\quad-a$ & $a$ & $196 \pm 8^{*}$ & $42 \pm 10^{* *}$ & $12 \pm 3^{*}$ & 6 \\
\hline \multicolumn{8}{|l|}{ Capsaicin treatment } \\
\hline Vehicle & $451 \pm 35$ & $112 \pm 22$ & $20 \pm 6$ & $172 \pm 21$ & $36 \pm 8$ & $63 \pm 12$ & 4 \\
\hline Capsaicin & $297 \pm 34^{* *}$ & $14 \pm 5^{* *}$ & $3 \pm 1^{*}$ & $178 \pm 16$ & $3 \pm 0.8^{* *}$ & $2 \pm 1^{* *}$ & 5 \\
\hline
\end{tabular}

All values represent means \pm SEM. $N=$ number of animals in each group. The area of quantification was $0.017 \mathrm{~mm}^{2}$.

Student's $t$ test results: significantly less than control at $p<0.05\left(^{*}\right)$ or $p<0.01\left({ }^{* *}\right)$ or than normal at $p<0.05(\dagger)$.

a The sampling area was a midline structure and could not be separated as treatment side versus control side.

\section{Discussion}

While SP-LI and CCK-8-LI have been shown to coexist in dorsal root ganglion cell bodies (Dalsgaard et al., 1983; Tuchscherer and Seybold, 1985a), only a preliminary report from our laboratory has reported the coexistence of SP-LI and CCK-8-LI in nerve fibers and terminals in various nuclei and fiber tracts in the rat spinal cord (Tuchscherer and Seybold, 1985b). In this study, we have presentcd data gencrated from a computerized image-processing approach that establishes the extent of coexistence of these peptides in varicosities within several areas of the spinal cord. Quantitative data concerning the density of immunoreactive varicosities within these regions and changes in densities with experimental manipulations was used to establish the relationship of immunoreactive varicosities to primary afferent neurons.

\section{The quantitative method}

Quantitative immunohistochemistry is emerging as a powerful tool in investigations of the nervous system. Many previous immunohistochemical studies have presented data regarding the densities of peptidergic varicosities in a qualitative way using relative density scales (Ljungdahl et al., 1978; Gibson et al., 1983; Sasek et al., 1984). Quantification of the level of immunoflourescence within a field has been possible using microfluorometry (Jensen et al., 1981; Schipper et al., 1984; Nagatsu et al., 1985). Computerized image analysis, however, has allowed the quantification of levels of immunoreactivity in individual perikarya (Benno et al., 1982), in addition to calculation of areas of immunoreactivity (Briski et al., 1983; Gross and Rothfeld, 1985). Our computerized image-processing approach has facilitated establishing the cocxistence of peptides within varicosities and has provided a mechanism for quantifying the densities of varicosities within specified regions of interest. The quantitative nature of the data has allowed statistical comparisons of experimental groups with controls in order to determine the relationship of immunoreactive varicosities with primary afferent neurons.

Although the method of computerized image analysis is powerful, the limitations of the approach must also be appreciated. Microscopic visualization and imaging of varicosities must be done within strict guidelines; and even within these guidelines, some error is to be expected. The sections we used were $5 \mu \mathrm{m}$ thick. The depth of field and resolution of the objective lens were calculated at 0.7 and $0.3 \mu \mathrm{m}$, respectively. Since the tissue thickness was greater than the depth of focus, all immunoreactive varicosities in the section were not quantified because they were not all within the plane of focus. However, the method was useful in establishing relative proportions of populations of immunoreactive varicosities. Another variable likely to introduce error is the possibility of spurious overlap of varicosities that would contribute to the error in quantification of coexistence. $\Lambda$ test was performed on images of immunofluorescent varicosities within the same region of tissue sections from different animals, in an effort to quantify the maximum spurious overlap that could occur. This amount was calculated to be $6 \%$ of the total coexistence in a region exhibiting the greatest degree of coexistence. A third variable arises from the method by presentation of the data as the calculated number of varicosities. Thus, fluorescence produced by structures other than varicosities, such as intervaricose axonal segments, could contribute to this number. While intervaricose regions of axons were observed to have a low level of fluorescence, these regions were considered to produce little error in the calculation of immunoreactive varicosities for 2 reasons: (1) The intensity of fluorescence of these regions was generally below the level of detection used for quantification of area of varicosities, and (2) the area of an intervaricose region within the plane of focus is much smaller than that of a varicosity. Therefore, in calculating the number of varicosities, intervaricose axon regions are believed to account for very few of the total pixels used in the calculation described in the Materials and Methods portion of this report. Finally, it is not likely that significant error occurs due to apposition of varicosities as part of a bundle of primary afferent fibers since preliminary data indicate little coexistence of SPLI and somatostatin within varicosities of the dorsal horn of the rat spinal cord (Tuchscherer and Seybold, unpublished observation).

\section{Characterization of immunoreactive varicosities}

The data we have presented support current immunohistochemical information that significant densities of SP-LI (Hökfelt et al., 1975b; Cuello and Kanazawa, 1978; Liungdahl et al., 1978; Barber et al., 1979; Gibson et al., 1983; = nd CCK-8-LI (Larsson and Rehfeld, 1979; Schroder, 1983; Conrath-Verrier et al., 1984) varicosities occur in the regions of the spinal cord selected for analysis. Our studies extend previous observations by providing quantitative comparisons of the densities of both 
SP-LI and CCK-8-LI varicosities and estimates of the amount of coexistence of these 2 peptides within each region studied.

Our studies also support and extend data describing the origin of SP-LI and CCK-8-LI varicosities in regions of the cord sclected for study. Many investigators have reported that SP-LI is markedly reduced in the superficial laminae of the dorsal horn following unilateral rhizotomy, indicating a primary afferent origin of the peptide within this region (Hökfelt et al., 1975a, b; Takahashi and Otsuka, 1975; Chan-Palay and Palay, 1977a, b; Seybold and Elde, 1980; Schultzberg et al., 1982; Massari et al., 1983). On the basis of our data from dorsal rhizotomized animals, it can be concluded that within laminae I + II, varicosities containing SP-LI which also coexists with CCK-8-LI are primarily of primary afferent origin. Varicosities within this region that contain SP-LI alone were not significantly depleted following unilateral dorsal rhizotomy and are therefore likely to be largely of spinal or descending origin. The changes we reported following unilateral rhizotomy are not likely due to nonselective degeneration of neuronal elements following ischemia which may result from the surgical manipulation since the density of SP-LI alone varicosities was the same, both ipsilateral and contralateral to the lesion.

With regard to the origin of CCK-8-LI in the superficial layers of the dorsal horn, several investigators have provided immunohistochemical evidence suggesting that much of this peptide immunoreactivity also arises from primary afferent neurons (Jancso et al., 1981; Maderdrut et al., 1982; Priestly et al., 1982; Conrath-Verrier et al., 1984). Our data are in agreement with these studies and suggest that all of the CCK-8-LI varicosities that also contain SP-LI and the majority of the CCK-8-LI alone varicosities within laminae I + II are of primary afferent neuron origin.

In contrast to these data, there have been conflicting reports, based on radioimmunoassay, as to whether levels of extractable CCK-8-LI are altered in the dorsal horn after dorsal rhizotomy (Marley et al., 1982; Schultzberg et al., 1982; Yaksh et al., 1982). The lack of an observable decrease in the levels of CCK-8 in extracts of the dorsal horn after dorsal rhizotomy in rat as determined by radioimmunoassay has raised the issue that CCK8-LI associated with primary afferent neurons as defined immunohistochemically may be due to cross-reactivity of the primary antisera with another peptide. Indeed, recent data on in situ hybridization of $\mathrm{cDN} \Lambda$ probes for $\mathrm{CCK}$ within dorsal root ganglia failed to localize CCK mRNA within dorsal root ganglia from rat, although dorsal root ganglia from guinea pig contain small and medium-sized neurons that hybridized with CCK probes (Rethelyi et al., 1986). Thus, it seems likely that a peptide related to, but not identical to, CCK- 8 is present in primary afferent neurons of the rat.

Hökfelt and coworkers have recently shown high cross-reactivity of their CCK-8 antisera with calcitonin gene-related peptide (CGRP) (Ju et al., 1986). The reportedly low levels of extractable CCK-8 immunoreactivity in dorsal root ganglia determined by radioimmunoassay (Schultzberg et al., 1982; Yaksh et al., 1982), compared with the assumed high levels of CGRP immunoreactivity determined by immunohistochemistry, supports the possibility that some of the CCK-8-LI observed with respect to primary afferent neurons by immunohistochemistry may be due to cross-reactivity with CGRP. For this reason, we addressed the cross-reactivity of the CCK-8 antiserum used in the present study with CGRP in more detail. In absorption controls, we found that $0.01 \mu \mathrm{M}$ CCK- 8 completely abolished immunostaining in the superficial laminae of the dorsal horn of the spinal cord (the region most affected by dorsal rhizotomy), while $100 \mu \mathrm{M} \mathrm{CGRP}_{1-37}$ (Pennisula) was required to abolish immunoreactivity observed with the CCK-8 antiserum. Furthermore, the patterns of immunostaining observed with antisera to CCK-8 and CGRP were different. The CCK-8 antiserum did not immunostain motor neurons in the hypoglossal nucleus or ventral horn of spinal segments C8 and L5, which were intensely immunoreactive with the CGRP antiserum. More importantly, varicosities within the piriform cortex and the lateral hypothalamus, which stained intensely with antisera to CGRP, did not react with our anti-CCK antiserum. For these reasons we believe that the CCK- 8 antiserum used in the present studies is specific for CCK- 8 or a related peptide and that our data on primary afferent neurons do not reflect CGRP immunoreactivity. Given the recent data that CCK mRNA is absent from rat DRG, the exact nature of the CCK8-LI material observed in the present study remains to be elucidated. However, our extensive characterization of the antiserum supports the hypothesis that we are visualizing a unique antigen contained within a discrete population of primary afferent neurons.

With regard to the origin of SP-LI and CCK-8-LI varicosities in other regions of the spinal cord, we present evidence showing a primary afferent origin for significant proportions of both peptides in the SPN. Almost all of the varicosities that contain both SP-LI and CCK-8-LI in this region are lost following unilateral dorsal rhizotomy surgery. Results of studies employing transganglionic transport of HRP in the rat showed that a significant number of visceral primary afferent fibers from the pelvic nerve project to the SPN (Nadelhaft and Booth, 1984). To the best of our knowledge, our data provide the first evidence establishing that a population of primary afferent fibers projecting to the SPN contain SP-LI and CCK-8-LI.

Our data also provide insight into chemically identified primary afferent neuron projections to DGC and lamina X. All 3 populations of immunolabeled varicosities (SP-LI alone, CCK8-LI alone, and SP-LI/CCK-8-LI) within the DGC and lamina $\mathrm{X}$ of the nonlesioned side, as well as the SP-LI/CCK-8-LI population within lamina $\mathrm{X}$ on the lesioned side were significantly depleted compared to normal animals. These data indicate that primary afferent fibers containing SP-LI, CCK-8-LI, and SP-LI/ CCK-8-LI project to DGC and lamina $X$ of the rat spinal cord. In addition, the greater decrease contralateral to the side of the lesion within lamina $X$ for SP-LI and CCK-8-LI alone suggests the possibility of a predominant contralateral projection for these chemically identified primary afferent fibers.

Our studies investigated not only which densities of SP-LI and CCK-8-LI varicosities in selected regions of the spinal cord were of primary afferent neuron origin, but also attempted to correlate populations of immunoreactive varicosities with unmyelinated versus thinly myelinated axons. We used neonatal administration of capsaicin as a tool to destroy predominantly small, unmyelinated C-fibers associated with primary afferent neurons. After neonatal treatment with capsaicin, SP-LI is chronically depleted from primary afferent neurons and their terminations but not from other CNS areas containing SP-LI (Gamse et al., 1980, 1981; Helke et al., 1981; Jancso and Kiraly, 1981; Gamse, 1982), supporting the selectivity of this neurotoxin for primary afferent neurons. Though one study reported that only C-fibers are destroyed by neonatally applied capsaicin (Nagy et al., 1983), studies from another laboratory using mor- 
phometric analysis of electron micrographs showed that in addition to a $90-95 \%$ loss of C-fibers, about $30 \%$ of the thinly myelinated fibers were destroyed by neonatal capsaicin treatment (Lawson and Nickels, 1980; Lawson, 1981). Thus, some loss of thinly myelinated fibers is to be expected.

The areas we studied exhibited significant depletion in the densities of peptide immunoreactive varicosities in response to neonatal capsaicin treatment. In all areas studied, CCK-8-LI alone and SP-LI/CCK-8-LI varicosity densities were significantly depleted (50-90\%) compared with vehicle-treated rats. In lamina $X, D G C$, and SPN, these populations of immunoreactive varicosities were nearly completely lost. Whereas previous studies have established that A-delta fibers project to lamina X (Light and Perl, 1979; Mense et al., 1981), the nearly complete loss of SP-LI/CCK-8-LI varicosities following capsaicin treatment suggests that a population of unmyelinated axons also projects to lamina $X$ and that these fibers contain both SP-LI and CCK-8-LI. Although we cannot exclude the possibility that SP-LI/CCK-8-LI varicosities reflect a population of thinly myelinated axons that are preferentially sensitive to capsaicin treatment (i.e., that the reported 30\% loss of thinly myelinated axons reflects differential sensitivity of chemically identified A-delta fibers), it is also of interest that a bundle of fibers ventral to the central canal exhibited a dramatic reduction of immunoreactive varicosities following neonatal capsaicin treatment. While fibers in this bundle have been shown to arise from primary afferent fibers (Nadelhaft and Booth, 1984), the magnitude of the capsaicin sensitivity of these fibers indicates that many are unmyelinated. This conclusion was subsequently confirmed by electron microscopy (K. E. Miller and V. S. Seybold, unpublished observation).

With regard to termination of primary afferent fibers in superficial laminae of the dorsal horn, it was noteworthy that the depletion of total CCK-8-LI varicosities from laminae I + II after neonatal capsaicin treatment was limited to approximately two-thirds of the amount seen following unilateral dorsal rhizotomy treatment. Moreover, the CCK-8-LI varicosities that remained following neonatal capsaicin treatment were predominantly localized in laminae I. Laminae I and II (outer) have been established by electrophysiological criteria to be primary termination sites of A-delta fibers (Light and Perl, 1979; Mense et al., 1981). Even though some loss of A-delta fibers may occur with capsaicin treatment, the magnitude of the population of capsaicin-resistant $\mathrm{CCK}-8$-LI varicosities and their location support the conclusion that a significant population of CCK-8LI varicosities within laminae I and II is associated with A-delta fibers.

Recent studies in rats showing that the mean cell size of dorsal root ganglion perikarya with C-size axons is significantly smaller than that of cells associated with A-delta size axons (Harper and Lawson, 1985) facilitate further comparisons between our studies of populations of immunoreactive varicosities in the spinal cord and immunoreactive perikarya in dorsal root ganglia. Our earlier work (Tuchscherer and Seybold, 1985a) demonstrated that SP-LI and CCK-8-LI coexist in a population of small cells in dorsal root ganglia. Our present data concerning the marked capsaicin sensitivity of SP-LI/CCK-8-LI varicosities in several regions of the spinal cord, and therefore their association with unmyelinated axons, are consistent with the relationship of small dorsal root ganglion cells with unmyelinated axons. Furthermore, the conclusion that some CCK-8-LI varicosities are associated with thinly myelinated axons is consistent with earlier observations of CCK-8-LI in intermediate-sized dorsal root ganglion perikarya. Some discrepancies with this relationship would seem to occur for other populations of immunoreactive cells. For instance, CCK-8 alone immunoreactive dorsal root ganglion cells were identified only within an intermediate size range in our earlier study. This observation appears inconsistent with present data that populations of CCK-8-LI alone varicosities in laminae I + II and the SPN are capsaicin sensitive. This discrepancy may be explained in 2 ways. Since the change in the superficial laminae was $50 \%$, a large proportion of this loss may reflect the nonselectivity of capsaicin. However, it is also important to note that our description of populations and proportions of coexistence in primary afferent perikarya was based on a study of spinal ganglion T10. It is possible that small dorsal root ganglion cells that display $\mathrm{CCK}-8-\mathrm{LI}$ alone may be present in dorsal root ganglia projecting to the segment of spinal cord analyzed in the present study (L6), and thus they may be reflected in our analysis of varicosities.

In conclusion, our studies have established that SP-LI and CCK-8-LI coexist in populations of varicosities in sensory and autonomic regions in the rat spinal segment L6. Moreover, within the superficial layers of the dorsal horn, those varicosities that contain both SP-LI/CCK-8-LI and CCK-8-LI alone are predominantly of primary afferent origin, whereas those that contain SP-LI alone are most likely of spinal or descending origin. The finding that capsaicin-insensitive fibers are present in laminae I and II (outer) also provides support of our previous work, which described CCK-8-LI in an intermediate-sized dorsal root ganglion cell population. Additionally, the work has shown that primary afferent fibers containing SP-LI and CCK8-LI project to deep laminae of the spinal cord and that a large proportion of these fibers are likely to be unmyelinated. Finally, it has been shown that computerized image analysis can be used to quantitate and compare varicosity densities in specific regions when using experimental paradigms.

\section{References}

Barber, R. P., J. E. Vaughn, J. R. Slemmon, P. M. Salvaterra, E. Roberts, and S. E. Leeman (1979) The origin, distribution and synaptic relationships of substance P axons in rat spinal cord. J. Comp. Neurol. 184: 331-352.

Benno, R. H., L. W. Tucker, T. H. Joh, and D. H. Reis (1982) Quantitative immunohistochemistry of tyrosine hydroxylase in rat brain. I. Development of a computer assisted method using the peroxidase anti-peroxidase technique. Brain Res. 246: 225-236.

Briski, K. P., B. L. Baker, and A. K. Christensen (1983) Effect of ovariectomy on the hypothalamic content of immunoreactive gonadotropin-releasing hormone in the female mouse as revealed by quantitative immunocytochemistry and radioimmunoassay. Am. J. Anat. 166: 187-208.

Cervero, F., and M. B. Plenderleith (1984) Dorsal root potentials are unchanged in adult rats treated at birth with capsaicin. J. Physiol. (Lond.) 357: 357-368.

Cervero, F., J. Shouenborg, B. J. Sjolund, and P. J. Waddell (1984) Cutaneous inputs to dorsal horn neurones in adult rats treated at birth with capsaicin. Brain Res. 301: 47-57.

Chan-Palay, V., and S. L. Palay (1977a) Immunohistochemical identification of substance $P$ cells and their processes in rat sensory ganglia and their terminals in the spinal cord: Light microscopic studies. Proc. Natl. Acad. Sci. USA 74: 3597-3601.

Chan-Palay, V., and S. L. Palay (1977b) Ultrastructural identification of substance P cells and their processes in rat sensory ganglia and their terminals in the spinal cord by immunocytochemistry. Proc. Natl. Acad. Sci. USA 74: 4050-4054.

Conrath-Verrier, M., M. Dietl, and G. Tramu (1984) Cholecystokininlike immunoreactivity in the dorsal horn of the spinal cord of the rat: A light and electron microscopic study. Neuroscience 13: 871-885. 
Cuello, A. C., and I. Kanazawa (1978) The distribution of substance $\mathrm{P}$ immunoreactive fibers in the rat central nervous system. J. Comp. Neurol. 178: 129-156.

Dalsgaard, L.-J., S. R. Vincent, T. Hökfelt, J. M. Lundberg, A. Daalstrom, M. Schultzberg, G. J. Dockray, and A. C. Cuello (1983) Coexistence of CCK and SP-like peptides in neurons of the dorsal root ganglia in the rat. Neurosci. Lett. 33: 159-163.

deGroat, W. C., I. Nadelhaft, C. Morgan, and T. Schauble (1978) Horseradish peroxidase tracing of visceral afferent and primary afferent pathways in the cat's sacral spinal cord using benzidine processing. Neurosci. Lett. 10: 103-108.

Erichsen, J. T., A. Reiner, and H. J. Karten (1982) Co-occurrence of substance P-like and Leu-enkephalin-like immunoreactivities in neurons and fibers of the avian nervous system. Nature 295: 407-409.

Gamse, R. (1982) Capsaicin and nociception in the rat and mouse. Possible role of substance P. Naunyn Schmiedebergs Arch. Pharmacol. 320: 205-216.

Gamse, R., P. Holzer, and F. Lembeck (1980) Decrease of substance $P$ in primary afferent neurons and impairment of neurogenic extravasation by capsaicin. Br. J. Pharmacol. 68: 207-213.

Gamse, R., S. E. Leeman, P. Holzer, and F. Lembeck (1981) Differential effects of capsaicin on the content of somatostatin, substance $P$, and neurotensin in the nervous system of the rat. Naunyn Schmiedebergs Arch. Pharmacol. 317: 140-148.

Gibson, S. J., J. M. Polak, S. R. Bloom, and P. D. Wall (1981) The distribution of nine peptides in rat spinal cord with special emphasis on the substantia gelatinosa and on the area around the central canal (lamina X). J. Comp. Neurol. 201: 65-79.

Gross, D. S., and J. M. Rothfeld (1985) Quantitative immunocytochemistry of hypothalamic and pituilary hormones: Validation of an automated, computerized image analysis system. J. Histochem. $\mathrm{Cy}$ tochem. 33: 11-20.

Harper, A. A., and S. N. Lawson (1985) Conduction velocity is related to morphological cell type in rat dorsal root ganglion neurones. $J$. Physiol. (Lond.) 359: 31-46.

Helke, C. J., J. A. DiMicco, D. M. Jacobowitz, and I. J. Kopin (1981) Effects of capsaicin administration to neonatal rats on the substance $P$ content of discrete brain regions. Brain Res. 222: 428-431.

Hökfelt, T., J. O. Kellerth, G. Nilsson, and B. Pernow (1975a) Experimental immunohistochemical studies on the localization and distribution of substance $P$ in cat primary sensory neurons. Brain Res. 100: $235-252$.

Hökfelt, T., J. O. Kellerth, G. Nilsson, and B. Pernow (1975b) Substance $P$ : Localization in the central nervous system and in some primary sensory neurons. Science 190: 889-890.

Hökfelt, T., R. Elde, O. Johansson, R. Luft, and A. Arimura (1976) Immunohistochemical evidence for separate populations of somatostatin and substance $\mathrm{P}$ containing primary afferent neurons in the rat. Neuroscience $1:$ 131-136.

Hökfelt, T., A. Ljungdahl, L. Terenius, R. Elde, and G. Nilsson (1977) Immunohistochemical analysis of peptide pathways possibly related to pain and analgesia: Enkephalin and substance P. Proc. Natl. Acad. Sci. USA 74: 3081-3085.

Jancso, G., and E. Kiraly (1981) Sensory neurotoxins: Chemically induced selective destruction of primary sensory neurons. Brain Res. 210: 83-89.

Jancso, G., E. Kiraly, and A. Jansco-Gabor (1977) Pharmacologically induced selective degeneration of chemosensitive primary afferent sensory neurons. Nature 270: 741-743.

Jancso, G., T. Hökfelt, J. Lundberg, E. Kiraly, E. Halasz, G. Nilsson, L. Terenius, J. Rehfeld, A. Steinbusch, A. Verhofsted, R. Elde, S. Said, and M. Brown (1981) Immunohistochemical studies on the effect of capsaicin on spinal and medullary peptide and monoamine neurons using antisera to substance $P$, gastrin/CCK, somatostatin, VIP, enkephalin, neurotensin, and 5-hydroxytryptamine. J. Neurocytol. 10: 963-980.

Jensen, R. H., J. S. Greenspan, D. Moore II, N. Talal, and J. R. Roubinian (1981) Quantitative immunofluorescence microscopy of renal glomeruli from mice exhibiting murine lupus erythematosus. J. Immunol. Methods 42: 343-353.

Jessell, T. M., L. L. Iversen, and A. C. Cuello (1978) Capsaicin-induced depletion of substance $\mathbf{P}$ from primary afferent neurons. Brain Res. 152: 183-188.

Jessell, T., A. Tsunoo, I. Kanazawa, and N. Ostuka (1979) Substance P: Depletion in the dorsal horn of rat spinal cord after section of the peripheral processes of primary sensory neurons. Brain Res. 168: 247259.

Ju, G., T. Hökfelt, J. A. Fischer, P. Frey, J. F. Rehfeld, and G. J. Dockray (1986) Does cholecystokinin-like immunoreactivity in rat primary sensory neurons represent calcitonin gene-related peptide? Neurosci. Lett. 68: 305-310.

Kanazawa, I., and T. Jessell (1976) Post-mortem changes and regional distribution of substance $P$ in the rat and mouse nervous system. Brain Res. 119: 447-453.

Kessler, J. A., and I. B. Black (1981) Similarities in the development of substance $P$ and somatostatin in peripheral sensory neurons: Effects of capsaicin and nerve growth factor. Proc. Natl. Acad. Sci. USA 78: 4644-4647

Konig, J. F. R., and R. A. Klippel (1963) The Rat Brain: A Stereotaxic Altas of the Forebrain and Lower Parts of the Brain Stem, Krieger, New York.

Kumazawa, T., and E. R. Perl (1976) Differential excitation of dorsal horn substantia gelatinosa and marginal neurons by primary afferent units with fine (A and C) fibers. In Sensory Functions of the Skin in Primates, X. Zotterman, ed., pp. 67-88, Pergamon, Oxford.

Kumazawa, T., and E. R. Perl (1978) Excitation of marginal and substantia gelatinosa neurons in the primate spinal cord: Indications of their place in the dorsal horn functional organization. J. Comp. Neurol. 177: 417-434.

Kuo, D. C., J. J. Oravitz, R. Eskay, and W. C. deGroat (1984) Substance $P$ in renal afferent perikarya identified by retrograde transport of fluorescent dye. Brain Res. 323: 168-171.

Larsson, L.-I. (1981) A novel immunocytochemical model system for specificity and sensitivity screening of antisera against multiple antigens. J. Histochem. Cytochem. 29: 408-410.

Larsson, L.-I., and J. F. Rehfeld (1979) Localization and molecular heterogeneity of cholecystokinin in the central and peripheral nervous system. Brain Res. 165: 201-218.

Lawson, S. N. (1981) Dorsal root ganglion neurons and dorsal roots: Effect of neonatal capsaicin. In Spinal Cord Sensation: Sensory Processing in the Dorsal Horn, A. G. Brown and M. Rethelyi, eds., pp. 57-58, Scottish Academic Press, Edinburgh.

Lawson, S. N., and S. M. Nickels (1980) The use of morphometric techiques to analyze the effect of neonatal capsaicin treatment on dorsal root ganglia and dorsal roots. J. Physiol. (Lond.) 303: 12P.

Lee, K. H., K. Chung, J. M. Chung, and R. E. Coggeshall (1986) Correlation of cell body size, axon size, and signal conduction velocity for individually labelled dorsal root ganglion cells in the cat. J. Comp. Neurol. 243: 335-346.

Light, A. R., and E. R. Perl (1979) Spinal termination of functionally identified primary afferent neurons with slowly conducting myelinated fibers. J. Comp. Neurol. 186: 133-150.

Light, A. R., D. L. Trevino, and E. R. Perl (1979) Morphological features of functionally defined neurons in the marginal zone and substantia gelatinosa of the spinal dorsal horn. J. Comp. Neurol. 186: 151-172.

Ljungdahl, A., T. Hökfelt, and G. Nilsson (1978) Distribution of substance P-like immunoreactivity in the central nervous system of the rat. I. Cell bodies and nerve terminals. Neuroscience 3: 861-943.

Maderdrut, J. L., T. L. Yaksh, P. Petrusz, and V. L. W. Go (1982) Origin and distribution of cholecystokinin-containing nerve terminals in the lumbar dorsal horn and nucleus caudalis of the cat. Brain Res. 243: 363-369.

Marley, P. D., J. I. Nagy, P. C. Emson, and J. F. Rehfeld (1982) Cholecystokinin in the rat spinal cord: Distribution and lack of effect of neonatal capsaicin treatment and rhizotomy. Brain Res. 238: 454459 .

Massari, V. J., Y. Tizabi, C. H. Park, T. W. Moody, C. J. Helke, and T. L. O'Donohue (1983) Distribution and origin of bombesin, substance $P$ and somatostatin in cat spinal cord. Peptides 4: 673-681.

Mense, S., A. R. Light, and E. R. Perl (1981) Spinal terminations of subcutaneous high threshold mechanoreceptors. In Spinal Cord Sensation, A. G. Brown and M. Rethelyi, eds., pp. 79-86, Scottish Academic Press, Edinburgh.

Morgan, C., I. Nadelhaft, and W. C. de Groat (1981) The distribution of visceral primary afferents from the pelvic nerve to Lissauer's tract and the spinal gray matter and its relationship to the sacral parasympathetic nucleus. J. Comp. Neurol. 201: 415-440.

Nadelhaft, I., and A. M. Booth (1984) The location and morphology of preganglionic neurons and the distribution of visceral afferent fibers 
from the rat pelvic nerve: A horseradish peroxidase study. J. Comp. Neurol. 226: 238-245.

Nadelhaft, I., J. Roppolo, C. Morgan, and W. C. deGroat (1983) Parasympathetic preganglionic neurons and visceral primary afferents in monkey sacral spinal cord revealed following application of horseradish peroxidase to pelvic nerve. J. Comp. Neurol. 216: 36-52.

Nagatsu, I., Y. Kawakani, N. Karasawa, H. Takahashi, K. Fujita, and T. Nagatsu (1985) Quantitative immunofluorescence of tyrosine hydroxylase in the adrenal medulla of spontaneously hypertensive rats. Experientia 41: 1054-1055.

Nagy, J. I., S. R. Vincent, W. A. Staines, H. C. Fibiger, T. D. Reisine, and H. I. Yamamura (1980) Neurotoxic action of capsaicin on spinal substance $\mathrm{P}$ neurons. Brain Res. 186: 435-444.

Nagy, J. I., S. P. Hunt, L. L. Iversen, and P. C. Emson (1981) Biochemical and anatomical observations on the degeneration of peptidecontaining primary afferent neurons after neonatal capsaicin. Neuroscience 10: 1923-1934.

Nagy, J. I., L. L. Iversen, M. Goedert, D. Chapman, and S. P. Hunt (1983) Dose-dependent effects of capsaicin on primary sensory neurons in the neonatal rat. J. Neurosci. 3: 399-406.

Panula, P., M. Hadjiconstantinou, H.-Y. T. Yang, and E. Costa (1983) Immunohistochemical localization of bombesin/gastrin-releasing peptide and substance $\mathbf{P}$ in primary sensory neurons. J. Neurosci. 3 . 2021-2029.

Priestly, J. V., S. Bramwell, L. L. Butcher, and A. C. Cuello (1982) Effect of capsaicin on neuropeptides in areas of termination of primary sensory neurons. Neurochem. Int. 4: 57-65.

Rethelyi, M., D. McGehee, and P. K. Lund (1986) Neuronal localization of cholecystokinin mRNAs in rat and guinea pig brain. Soc. Neurosci. Abstr. 12(2): 1041.

Sasek, C. A., V. S. Seybold, and R. P. Elde (1984) The immunohistochemical localization of nine peptides in the sacral parasympathetic nucleus and the dorsal gray commissure in the rat spinal cord. Neuroscience 12: 855-873.

Scadding, J. W. (1980) The permanent anatomical effects of neonatal capsaicin on somatosensory nerves. J. Anat. 131: 473-484.

Schipper, J., T. R. Werkman, and F. J. H. Tilders (1984) Quantitative immunocytochemistry of corticotropin-releasing factor (CRF). Studies on non-biological models and on hypothalamic tissues of rats after hypophysectomy, adrenalectomy, and dexamethasone treatment. Brain Res. 253: $111-118$
Schroder, H. D. (1983) Localization of cholecystokinin-like immunoreactivity in the rat spinal cord, with particular reference to the autonomic innervation of the pelvic organs. J. Comp. Neurol. 217: 176-186.

Schultzberg, M., G. J. Dockray, and R. G. Williams (1982) Capsaicin depletes CCK-like immunoreactivity detected by immunohistochemistry, but not that measured by radioimmunoassay in the rat dorsal spinal cord. Brain Res. 235: 198-205.

Seybold, V. S., and R. P. Elde (1980) Immunohistochemical studies of peptidergic neurons in the dorsal horn of the spinal cord. J. Histochem. Cytochem. 28: 367-370.

Stefanini, M., C. DeMartino, and L. Zamboni (1967) Fixation of ejaculated spermatozoa for electron microscopy. Nature 216: 173-174

Stroink, A., P. Micevych, V. L. W. Go, and T. L. Yaksh (1982) Immunohistochemical and radioimmunoassay studies of substance $P$ in the dorsal horn following ganglionectomy. Soc. Neurosci. Abstr. 8: 583.

Stroink, A., P. Micevych, and T. L. Yaksh (1982) Immunohistochemical studies of substance $P$ and cholecystokinin recovery after ganglionectomy. Anat. Rec. 202: 183A.

Sugiura, Y., C. L. Lee, and E. Perl (1986) Central projections of identified, unmyelinated (C) afferent fibers innervating mammalian skin. Science 234: 358-361.

Takahashi, T., and M. Otsuka (1975) Regional distribution of substance $P$ in the spinal cord and nerve roots of the cat and the effect of dorsal root section. Brain Res. 87: 1-11.

Tuchscherer, M. M., and V.S. Seybold (1985a) Immunohistochemical studies of substance $P$, cholecystokinin-octapeptide, and somatostatin in dorsal root ganglia of the rat. Neuroscience 14: 593-605.

Tuchscherer, M. M., and V. S. Seybold (1985b) Evidence for coexistence of substance $P$ and cholecystokinin in fibers and terminals in the dorsal horn of the rat spinal cord. Anat. Rec. 211: 200A.

Wessendorf, M. W., and R. P. Elde (1985) Characterization of an immunofluorescence technique for the demonstration of co-existing neurotransmitters within nerve fibers and terminals. J. Histochem. Cytochem. 33: 984-994.

Yaksh, T. L., E. O. Abay, and V. L. W. Go (1982) Studies on the location and release of cholecystokinin and vasoactive intestinal polypeptide in rat and cat spinal cord. Brain Res. 242: 279-290. 